\title{
Topographic controls on vegetation index in a hilly landscape: a case study in the Jiaodong Peninsula, eastern China
}

\author{
Yetang Wang $\cdot$ Xiyong Hou $\cdot$ Maojian Wang • \\ Li Wu $\cdot$ Lanlan Ying $\cdot$ Yinyin Feng
}

Received: 12 October 2011/Accepted: 26 November 2012/Published online: 12 December 2012

(C) Springer-Verlag Berlin Heidelberg 2012

\begin{abstract}
This study examined topographic influence on spatial and temporal variability in the normalized difference vegetation index (NDVI) derived from the Satellite Pour l'Observation de la Terre-Vegetation at the regional and landscape scales in the Jiaodong Peninsula. The generalized additive models were used to quantify the spatial variation of NDVI attributable to local terrain and topographically related variables including altitude, exposure to incoming solar radiation, topographic wetness index, distance to the nearest stream and distance from the coast. NDVI distribution shows significant dependence on topography. The variables explained $38.3 \%$ of variance in NDVI at the peninsula, and $30-45.3 \%$ of variance in NDVI at the woodland, cropland, and grassland landscapes. At the Jiaodong Peninsula scale, NDVI is influenced primarily by distance from the coast. However, topographic wetness index has the most explanatory power for NDVI at the woodland, cropland, and grassland landscapes. Through a statistical nonparametric correlation analysis (Spearman's $r$ ), the study indicates that spatial distribution of NDVI changes during the period 1998-2009 and future change trend of persistence determined by Hurst
\end{abstract}

Y. Wang - M. Wang $\cdot$ Y. Feng

Shandong Provincial Key Laboratory of Marine Ecological Restoration, Shandong Marine Fisheries Research Institute, Yantai 264006, China

\section{Y. Wang $(\bowtie)$}

State Key Laboratory of Cryospheric Sciences, Cold and Arid Regions Environmental and Engineering Research Institute, CAS, Lanzhou 73000, China

e-mail: wangyetang@163.com

X. Hou $\cdot$ L. Wu $\cdot$ L. Ying

Yantai Institute of Coastal Zone Research,

Chinese Academy of Sciences, Yantai 264003, China exponent is closely associated with topography and topography-based attribution. These results highlight the importance of topographic changes at landscape and regional scales as an important control factor on NDVI patterns.

Keywords Topography $\cdot$ Spatial variation $\cdot$ Temporal variation · NDVI

\section{Introduction}

Vegetation cover is thought to have considerable impacts on all of the processes in terms of land and atmosphere. It affects local and regional climate (e.g., Arora 2002; Douville et al. 2000), and hydrologic balance of the land surface (e.g., Eugster et al. 2000), stores carbon stocks (Cernusca et al. 1998), reduces erosion, and partially or totally controls some natural hazards such as slides, rockfalls, debris flow and floods (e.g., Berger and Rey 2004; Brang et al. 2001). Therefore, it is of great importance to analyze spatial and temporal patterns of vegetation for natural environmental threat evaluation. The knowledge of the spatial and temporal variability in vegetation cover is also useful for modeling biogeochemical cycles and climate feedbacks.

Vegetation patterns are inherently influenced by the environmental heterogeneity. In particular, topographic heterogeneity imposes environmental constraints on vegetation development by producing complex substrates with variable structure, hydrology, and chemistry (Bledsoe and Shear 2000). Considerable studies have attempted to relate topography to vegetation type and composition (e.g., Franklin et al. 2000; Pfeffer et al. 2003; Abbate et al. 2006; Reed et al. 2009; White and Hood 2004), the abundance 
and distribution of species (e.g., Morzaria-Luna et al. 2004; Meentemeyer et al. 2001), vegetation diversity (Tilman 1982; Keddy 1990; Poulos and Camp 2010) and vegetation greenness (White et al. 2005; Deng et al. 2007), even across different spatial scales. However, there are few studies on what extent topographic attributions control normalized difference vegetation index (NDVI) and the potential dependence of vegetation fluctuation over time on topography.

With much improvement in resolution, dependability and accessibility of digital elevation models (DEM), digital terrain analysis techniques become popular to improve the efficiency of vegetation pattern estimate and modeling. For such efforts, it is crucial to quantify topography impact on vegetation and identify which topographic environments support the highest vegetation cover. Additionally, such quantitative information is beneficial for landscape management improvement and guidance for potential re-vegetation efforts.

NDVI provides information about vegetation communities (Reed et al. 1994), correlates closely with green leaf biomass and green leaf area index (Boone et al. 2000; Chen and Brutsaert 1998), and can be considered a surrogate for vegetation production due to its robust relationship with vegetation biomass (Svoray and Karnieli 2011). In recent decades, despite many other vegetation indices, NDVI is still gaining more and more attention and confidence for vegetation pattern evaluation (e.g., Ceccato et al. 2001; Chuvieco et al. 2002; Serrano et al. 2000), and also continues to play an important role in the future studies of ecosystem dynamics. In particular, NDVI data derived by satellite such as the advanced very high resolution radiometer (NOAA-AVHRR), the moderate resolution imaging spectroradiometer (TERRA-MODIS) and SPOT-VGT have been widely used to evaluate vegetation distribution and dominant species, classify land cover, predict primary production and detect plant stress at different spatial scales.

The objective of this study is to quantify the relative contributions of each topographic and topographically related attribution to spatial patterns of NDVI in the Jiaodong Peninsula using newly available statistical techniques, generalized additive models (GAMs), and to better understand the impact of the major forces of topography on the temporal variation of NDVI.

\section{Study area}

Jiaodong Peninsula is located within $35^{\circ} 35^{\prime} \mathrm{N}$ and $38^{\circ} 23^{\prime} \mathrm{N}$ latitude, and $119^{\circ} 30^{\prime} \mathrm{E}$ and $122^{\circ} 42^{\prime} \mathrm{E}$ longitude, neighboring the Yellow Sea and Bohai Sea, with a total extension of $30,085 \mathrm{~km}^{2}$ (Fig. 1). The peninsula has a rocky coastline with cliffs, bays, and islands. The total length of coastal lines is $2,528 \mathrm{~km}$. Elevations range from sea level at the coast to $1,133 \mathrm{~m}$ on Laoshan Peak. The area of mountainous regions is $18,622 \mathrm{~km}^{2}$, accounting for $62 \%$ of the total. Most of rivers having their headwaters in the central Jiaodong Peninsula belong to monsoon rain originating from mountain torrents. These rivers run south and north, respectively, until they flow into the sea.

Jiaodong Peninsula is characterized by a warm temperate, wet monsoon climate with wet hot summers and dry cold winters. Annual precipitation ranges from 650 to $850 \mathrm{~mm}$, with a maximum in summer (June-August). Southern peninsula receives $800 \mathrm{~mm}$ of annual precipitation, and annual precipitation is about $600 \mathrm{~mm}$ in the northwestern parts of the peninsula. Annual mean maximum temperature is about $25^{\circ} \mathrm{C}$, and annual mean minimum temperature between -3 and $-1{ }^{\circ} \mathrm{C}$.

According to 1-km spatial resolution land use/land cover data (2005) for Jiaodong Peninsula (Fig. 1c), which is available at http://www.resdc.cn/first.asp, the peninsula consists of $56.9 \%$ croplands, $14.8 \%$ grasslands, $11.6 \%$ costal protection forests and small forests, and $16.8 \%$ the rest. The remaining regions are covered by villages $(6.5 \%)$, cities $(4.3 \%)$, roads and channels $(2.6 \%)$, small lakes and ponds $(3.1 \%)$ and unused land $(0.3 \%)$.

\section{Data and methods}

Data

The NDVI data used in this study were S10 (10-day synthesis) products of SPOT-VGT (VGT-S10) from April 1998 to December 2009. VGT-S10 is 1-km spatial resolution maximum-value composite products deriving from VEGETATION instrument onboard the SPOT 4 and SPOT 5 satellite platforms. These products provide data in the four spectral bands. The spectral bands are blue $(0.43-0.47 \mu \mathrm{m})$, red $(0.61-0.68 \mu \mathrm{m})$, near infrared (NIR $0.78-0.89 \mu \mathrm{m}$ ), and shortwave infrared (SWIR 1.58$1.75 \mu \mathrm{m})$. SPOT-VGT data were pre-processed including atmospheric correction for ozone, aerosols and water vapor, the geometrical and radiometrical correction, and masking procedures to improve data quality.

Altitude (ALT), slope (S), aspect (AS), annual mean incident solar radiation (ISR), topographic wetness index (TWI), distance to the nearest coast (DC), and distance to the nearest stream (DS) were used as independent predictors to explain variation in NDVI. These variables were selected because they are widely regarded to exert a stable control on vegetation (e.g., Dargie 1984; Franklin 1995; White et al. 2005; Deng et al. 2007). In addition, population density (PD) and distance to the urban site (DUS) were also used. The 90-m cell size Shuttle Radar Topography Mission (SRTM) from Consultative Group for 

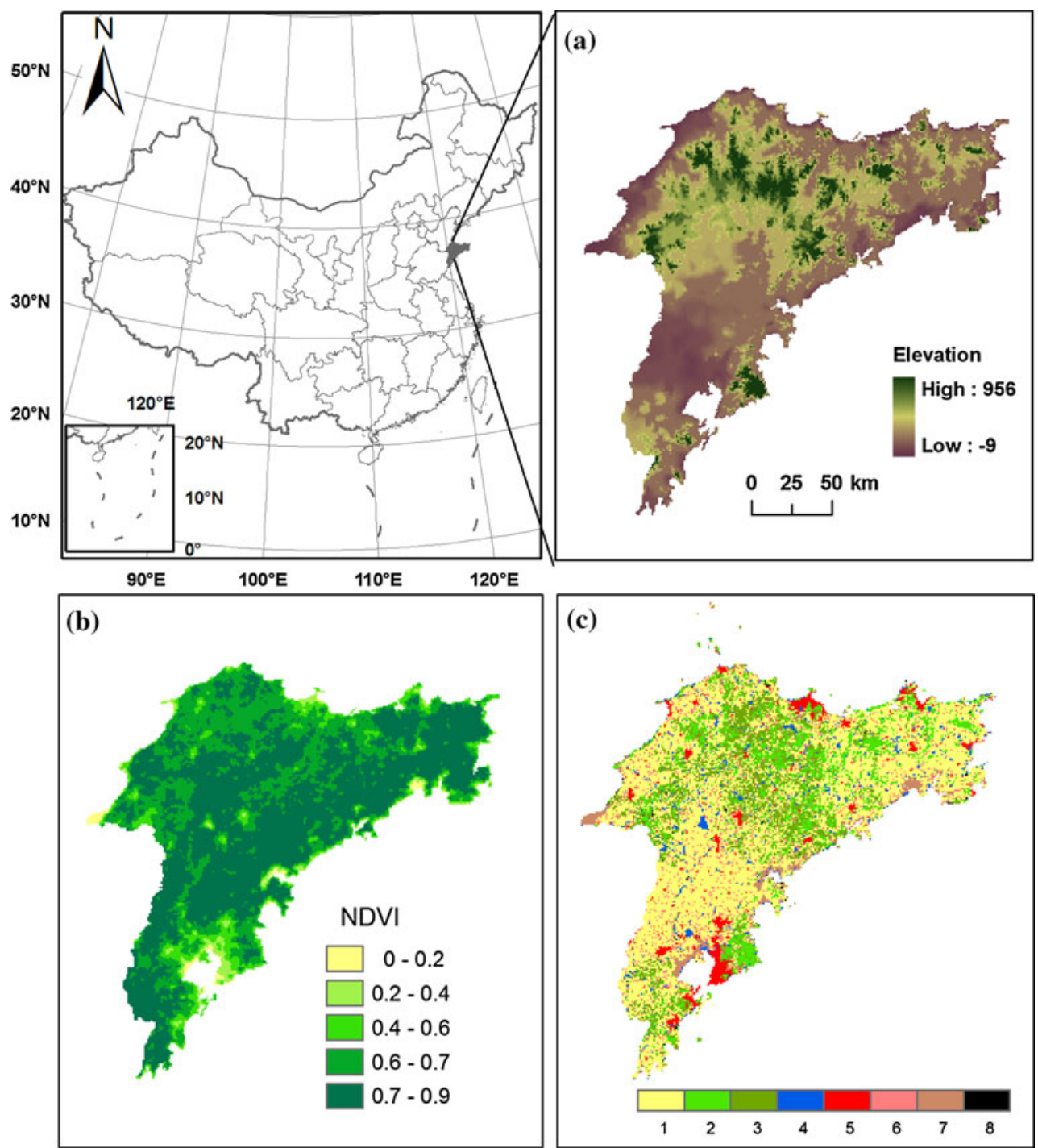

Fig. 1 Study area showing a DEM, b spatial distribution of annual NDVI, c land use types: 1 croplands, 2 forests, 3 grassland, 4 water body, 5 cities, 6 villages, 7 roads, channels, and industrial and mining lands, 8 unused land

International Agriculture Research Consortium for Spatial Information (CGIAR-CSI, available at http://srtm.csi. cgiar.org/) was used to produce ALT, S, and AS using ArcGIS 9.3. For reasons of spatial coherence, SRTM DEM were resampled to $1-\mathrm{km}$ spatial resolution and co-registered to the NDVI data using a nearest neighbor resampling algorithm. ISR for each cell of SRTM in the study area was estimated using MiraMon GIS (Pons 1998). The program takes into account of site latitude, ALT, orientation, shading effects, daily shifts in solar angle (hourly) and solar incidence angle for each cell, Earth-Sun distance (monthly) and the atmospheric extinction effect. TWI developed by Beven and Kirkby (1979) was used to characterize the influence of topographic variation on the spatial variation of soil water content. It is calculated as:
$\mathrm{TWI}=\ln \left(A_{s} / \tan \beta\right)$

where $A_{s}$ is the local upslope area draining through a certain point per unit contour length and $\beta$ is the local slope. $A_{s}$ was calculated in ArcInfo using slope and aspect to estimate how many upstream pixels drained into a candidate pixel. DC was estimated using the coastline layer of the digital line graphs (DLGs) available at the 1:250,000 scale generated by National Geomatics Center of China in 2002 for Jiaodong Peninsula. The DS variable was calculated for perennial streams and lakes based on the hydrography layer of DLGs. The DUS was generated using the urban location layer of DLGs. Population density gridded data at $1-\mathrm{km}$ resolution come from China sharing infrastructure of earth system science. 


\section{Methods}

Inter-annual changes of NDVI dynamics from 1998 to 2009 were analyzed by a linear regression. The slope of the regression was used to quantify the change of NDVI over time. Future persistence of the change trend in NDVI over the study period was determined by Hurst exponent $(H)$ developed by Hurst (1951), which provides a robust measurement of long memory in time series. The values of $H$ ranging from 0 to 1 can be classified into three categories: $0<H<0.5, H=0.5$ and $0.5<H<1$. If $H$ is less than 0.5 , the time series of NDVI is an anti-persistent series, meaning future anti-trend variation of the time series. If $H$ is equal to 0.5 , the time series of NDVI is random without consistency. If $H$ is greater than 0.5 , the time series of NDVI is a persistent series, meaning the future same change trend of the time series. Nonparametric correlation analysis was employed to examine the effect of topography on temporal variation of NDVI dynamics at the peninsula.

GAMs (e.g., Hastie and Tibshirani 1987; Guisan and Zimmermann 2000) provide a flexible nonparametric means that can deal with non-normal data and non-linear relationship between the response and the set of predictor variables. GAMs are the extensions of linear regression models that use the data to automatically estimate the appropriate functional relationship for each predictor (Guisan et al. 2002). In a GAM, a link function is utilized to establish a relationship between the mean of the response variable and a smooth function of the predictor variable(s). A GAM can be expressed as follows:

$g\left(E\left(y_{i}\right)\right)=\beta_{0}+s_{1}\left(x_{1 i}\right)+s_{2}\left(x_{2 i}\right)+\cdots+s_{p}\left(x_{p i}\right)$

where $s_{p}$ is smooth function, and $x_{p}$ is a predictor variable, and $g$ is a link function that associates the linear predictor with the expected value of the response variable.
To understand any spatial patterns of NDVI response to land use, data analysis consisted of the investigation of the NDVI-topography relationships based on a stratification of the study area into major land use categories, i.e., cropland, grassland and woodland. Variation in explained deviance when each predictor variable was eliminated from the model was used to estimate the relative contribution of predictor variables.

The data were split randomly into two groups, where $70 \%$ of the data were used to calibrate the model, while the left out $30 \%$ were used to test the fitted model (Guisan and Zimmermann 2000). The mean absolute error (MAE) and the root mean square error (rRMSE) relative to the absolute observed value were used to evaluate the fitted GAM performance.

\section{Results}

Temporal variation of NDVI dynamics

The trends determined by a linear regression to all the pixels indicate a high spatial heterogeneity in annual NDVI variation during the period 1998-2008 (Fig. 2). About $9.4 \%$ of Jiaodong Peninsula experiences moderate and significant decreasing trends $\left(<0.005 \mathrm{a}^{-1}\right)$ of NDVI. They mainly occur in the coast areas, especially the cities probably due to the intensifying urbanization since the late 1990s. NDVI pixels with upward trends cover more than $84 \%$ of the peninsula. Furthermore, about $34.6 \%$ of the pixels have a distinct increasing trend $\left(>0.01 \mathrm{a}^{-1}\right)$, which occur in the central peninsula where crop is the dominant vegetation type.

Hurst exponent of annual NDVI time series shows distinct increase from the coast to the inland Jiaodong
Fig. 2 Spatial distribution of NDVI change trend and Hurst exponent at the Jiaodong Peninsula from 1998 to 2009

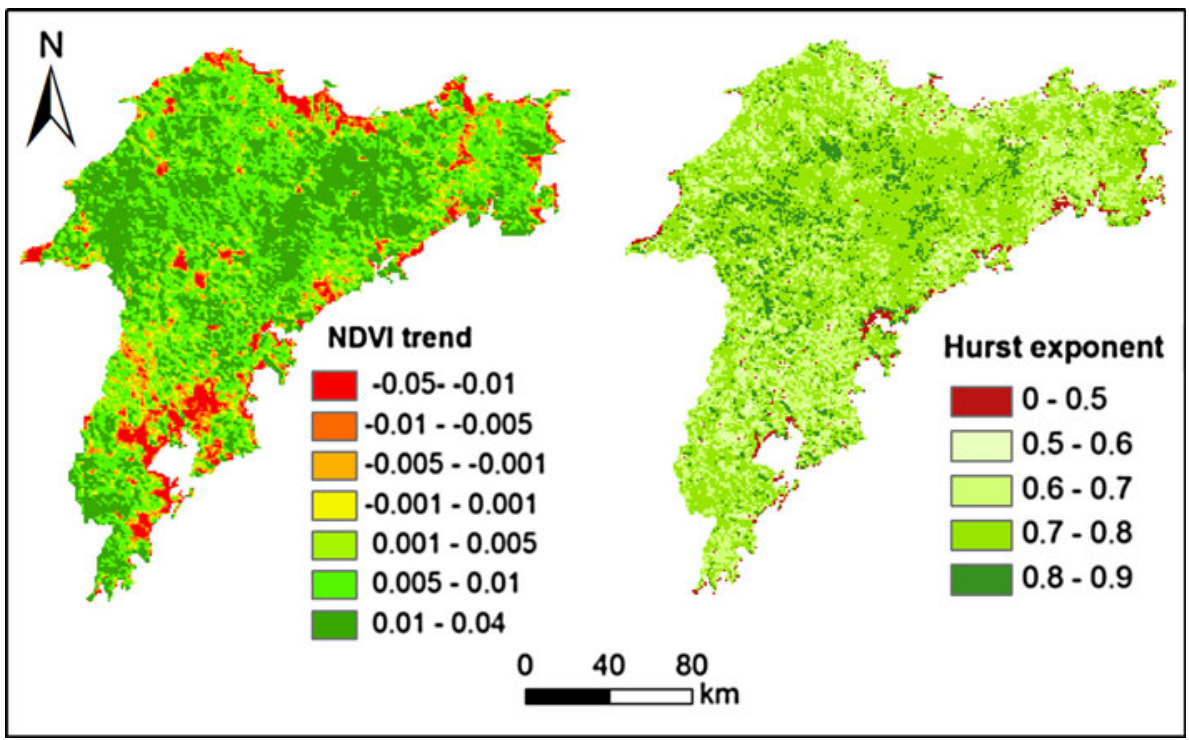


Table 1 The correlation coefficient between topographic and topography-based variables with Hurst exponent and linear trend slope of NDVI change during 1998-2009, respectively

All the coefficients but the bold values are at a significance level of $p<0.001$

\begin{tabular}{|c|c|c|c|c|c|c|c|c|}
\hline & \multicolumn{2}{|l|}{$\begin{array}{l}\text { Jiaodong } \\
\text { Peninsula }\end{array}$} & \multicolumn{2}{|c|}{ Corp landscape } & \multicolumn{2}{|c|}{ Meadow landscape } & \multicolumn{2}{|c|}{ Forest landscape } \\
\hline & $\begin{array}{l}\text { Hurst } \\
\text { exponent }\end{array}$ & Slope & $\begin{array}{l}\text { Hurst } \\
\text { exponent }\end{array}$ & Slope & $\begin{array}{l}\text { Hurst } \\
\text { exponent }\end{array}$ & Slope & $\begin{array}{l}\text { Hurst } \\
\text { exponent }\end{array}$ & Slope \\
\hline Altitude & 0.278 & 0.376 & 0.224 & 0.311 & 0.239 & 0.211 & 0.266 & 0.295 \\
\hline Slope & 0.127 & 0.183 & 0.073 & 0.122 & 0.084 & 0.058 & 0.075 & 0.047 \\
\hline $\begin{array}{l}\text { Topographic wetness } \\
\text { index }\end{array}$ & 0.022 & 0.004 & 0.007 & 0.011 & 0.056 & -0.054 & 0.059 & -0.026 \\
\hline $\begin{array}{l}\text { Distance to the nearest } \\
\text { stream }\end{array}$ & -0.018 & 0.055 & 0.016 & 0.079 & -0.046 & 0.008 & -0.042 & 0.037 \\
\hline Distance to the coast & 0.251 & 0.255 & 0.202 & 0.153 & 0.313 & 0.291 & 0.287 & 0.28 \\
\hline
\end{tabular}

Peninsula (Fig. 2). Most of the peninsula has high persistence of NDVI trends in the future with $H$ greater than 0.5 . Moreover, the central peninsula with the dominant vegetation of crop experiences a higher persistence $(>0.8)$ of NDVI trends after the study period. $H$ with the value less than 0.5 covering only $2 \%$ of the peninsula mainly occurs in the coastal regions with the significant decrease trend of NDVI. This indicates anti-trends of future NDVI variation.

Topographic influence on temporal variation of NDVI dynamics

As Table 1 shown, there is low $(r<0.38)$ but very significant $(p<0.001)$ correlation between nearly all tested topographic and topographically related variables and magnitude and persistence of NDVI change trends in the peninsula, cropland, grassland and woodland landscapes, respectively. In spite of the very limited explanatory power $(<15 \%)$ for the NDVI variability trend due to the other factors affecting vegetation variation such as climate, vegetation type and soil, the temporal variability explained by the topography is persistent and significant.

\section{Topographic controls on spatial patterns of NDVI}

GAM fits based on $R^{2}$ values were higher when the two human impact terms were included (Table 2). An overall assessment of the regression statistics presented in Table 2 suggests that the performance of all models is less successful with $R^{2}$ values for the training data ranging from 0.3 to 0.45 . Furthermore, the accuracy of models based on test data is lower than that of models based on training data. The magnitude of the differences between the observation and prediction by GAMs ranged from 3.5 to $5.4 \%$. The RSMEs were between 6.9 and $12.5 \%$.

Topographical and topographically related variables clearly affect spatial distribution of NDVI at the regional and landscape scales. The models fitted using these variables explained the variation of NDVI in the total study area, cropland, grassland, and woodland landscapes
Table 2 Explanatory variance (only using training data) and predictive accuracy (using independent test data) of the fitted models for NDVI in the total study area, cropland, grassland and woodland

\begin{tabular}{lllll}
\hline & $\begin{array}{l}\text { Explanatory } \\
\text { variance }\end{array}$ & \multicolumn{3}{l}{ Predictive accuracy } \\
\cline { 3 - 5 } & $R^{2} \times 100$ & $R^{2} \times 100$ & $\begin{array}{l}\text { MAE } \\
(\%)\end{array}$ & $\begin{array}{l}\text { rRSME } \\
(\%)\end{array}$ \\
\hline $\begin{array}{c}\text { All the } \\
\text { peninsula }\end{array}$ & 38.3 & 38.6 & 5.54 & 12.22 \\
Croplands & 30.3 & 27.5 & 3.7 & 7.25 \\
Meadow & 35 & 27.9 & 3.39 & 7.13 \\
Forest & 45.4 & 39.3 & 3.51 & 6.9 \\
\hline
\end{tabular}

$M A E$ Mean absolute error, $r R M S E$ relative root mean square error

(Table 3). For the total study area, $38.3 \%$ of variation in NDVI patterns was explained. In the cropland and grassland landscapes, deviance explained by topographic variables remained $<35 \%$. The variables captured $45.3 \%$ of variation in woodland NDVI. When adding two anthropic factors (PD and DUS) to the models, explained deviance increases by $>5 \%$ especially for the total study area (10.4\% increase), suggesting human management and disturbance such as urbanization, agricultural activity, and grass/shrub planting and cutting may have badly affected the spatial variation of NDVI.

The final set of predictor variables in the fitted GAMs and their importance differs considerably. Although a significant portion of the variance in the data was explained by ALT, ISR and DS, their importance is low (Table 3). These simple topographical and topographically related variables integrate a variety of environmental controls on NDVI such as rainfall gradients, water flow, and radiant energy. DC explained the highest amount of spatial variation of NDVI in the total study area. TWI consistently contributed the most explanatory power to the spatial variation in NDVI in woodland, cropland, and grassland landscapes. Topographically mediated redistribution of rainfall is responsible for moisture limitations affecting plant greenness. 
Table 3 Summary of GAM with significant predictor variables $(p<0.001)$, change in explained deviance when dropping predictor variables from the fitted model

\begin{tabular}{|c|c|c|c|c|c|c|c|c|c|c|c|}
\hline & All variables & PD and DUS & ALT & TWI & $\mathrm{S}$ & AS & ISR & DS & $\mathrm{DC}$ & PD & DUS \\
\hline All the peninsula & 48.7 & 38.3 & 1.5 & 2.2 & - & - & 0.9 & 0.7 & 10.1 & 8.5 & 0.7 \\
\hline Croplands & 36.9 & 30.6 & 2.3 & 4.4 & - & 0.4 & 3.1 & 0.9 & 11.4 & 3.5 & 2 \\
\hline Meadow & 40 & 35 & 2.1 & 4.5 & 0.6 & - & 0.9 & 0.7 & 6.1 & 2.3 & 2.3 \\
\hline Forest & 49.3 & 45.4 & 0.9 & 8.4 & - & - & 2.7 & 1.3 & 8.5 & 2.9 & 0.7 \\
\hline
\end{tabular}

Figures 3 and 4 show the response curves of each topographic and topographically related variables to NDVI in the total area, cropland, grassland and woodland landscapes. NDVI in the different land use units varied significantly according to local topography and topographically mediated conditions. The relationships between NDVI and topographically related variables were not consistent in the different landscapes. However, it was common that NDVI in the coast area increased with distance from the coast. In addition to distance from the coast, annual mean ISR, TWI and DS were found to be suitable for evaluating NDVI distribution.

\section{Discussion}

Although the variability in climate factors such as temperature and precipitation was an important driver of vegetation dynamics, topography was gradually considered a control factor on vegetation dynamics (Fu et al. 2009). White et al. (2005) explored the control of topographic variables such as elevation, slope, aspect, and proximity to moisture convergence zones on the interannual variations of NDVI over America through a data mining technique and elevation and slope exhibit the predominant controls on the NDVI response to climate oscillations. Peng et al. (2012) showed that $H$ of NDVI change over the Tibetan Plateau is closely associated with elevation. In Jiaodong Peninsula, woodland, cropland, and grassland landscapes, topography and topography-based attributes contribute more to the spatial patterns of temporal change in NDVI and $H$ (Table 1). Among the topographical and topography-based variables, the correlation between ALT and DS with spatial patterns in slope of NDVI trends and $H$ is stronger than the other attributes (Table 1). The distinct weakening trends of NDVI were mainly below $100 \mathrm{~m}$ of the peninsula. In contrast, NDVI in the inland with ALT of above $300 \mathrm{~m}$ shows significant increasing trend. The increasing trends in NDVI changes gradually become more prominent from the coast to the inland. It is interesting that some coast areas with weakening trends in NDVI have the values of $H$ below 0.5 , promising an anti-trend of future NDVI variation in these regions.
It is noted that urbanization and industrialization in and around cities increase the loss of forested and agricultural land to urban development, and thus result in NDVI decline. Exploitation of the coastal wet lands also leads to the loss of vegetation cover (Liu et al. 2010). With the implementation of environmental protection policies, protection of the mountain vegetation may to a certain extent promote the increasing of NDVI in the inland peninsula.

Previous studies have demonstrated that GAMs are very useful tools to predict and explain the distinct features of biodiversity such as species presence/absence, and species richness (e.g., Bio et al. 1998; Lehmann et al. 2002).In this study, GAMs were used to examine the effect of topography on spatial patterns of NDVI. The model has a non-linearity advantage for analyzing the response of the predictors (ALT, ISR, TWI, DC, and DS) to the response variable (spatial patterns of NDVI). Our results identified DC as a good predictor of mean NDVI distribution in the Jiaodong Peninsula and three major land use categories, i.e., cropland, grassland and woodland. Vegetation in the coastal areas is liable to very harsh environments such as deficiency in major nutrients, high salt spray and lack in water. In addition, the coastal regions of the peninsula are under threat, mainly from inappropriate firing, exploitation, building developments and recreational activities. These threats gradually decline with the increase in the distance from the coast. Probably due to these urbanization process and rapid growth of population in the coastal cities, vegetation green has a decrease trend in the regions in recent decades. A considerable portion of spatial variation of NDVI in the cropland, grassland, especially woodland landscape can be explained by TWI because the index describes the topographically constrained redistribution of precipitation and is regarded a surrogate for soil water content affecting vegetation. This agrees well with the previous studies emphasizing the significant relationship between the index and NDVI (e.g., Deng et al. 2007; Reed et al. 2009). At the peninsula, woodland often has relatively steep terrain which influences spatial distribution of saturation and run-off generation zones. Therefore, the relatively steep terrain in woodland may constrain the soil moisture for vegetation growth. In addition to DC and TWI, ISR, ALT and DS also contribute to NDVI 

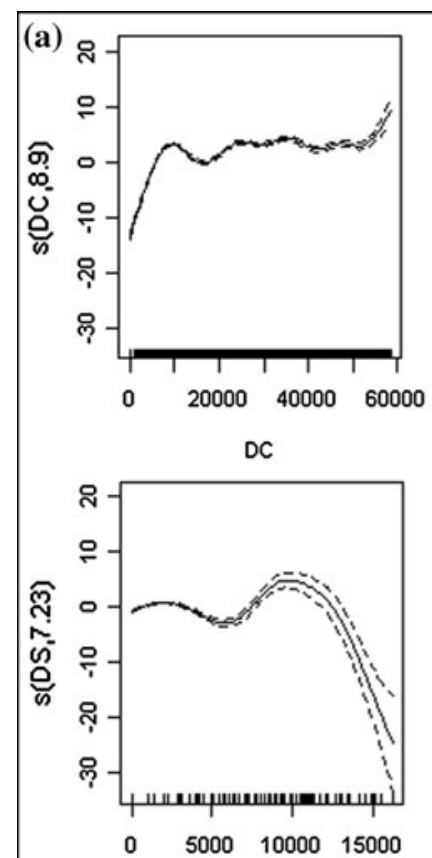

DS

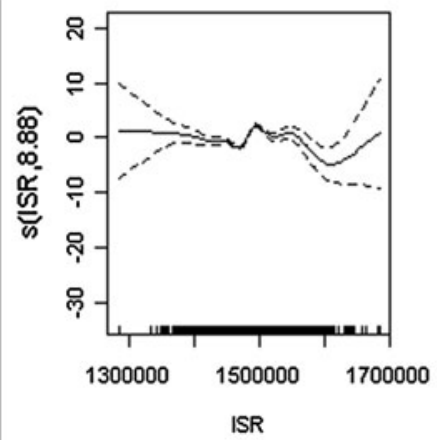

Fig. 3 Response curves of NDVI in the total study area (a) and woodland (b) to smooth contributing terms: altitude $(A L T)$, slope $(S)$, aspect $(A S)$, annual mean incident solar radiation $(I S R)$, topographic

distribution. The variations in topographically induced incoming radiation can result in corresponding soil moisture variations (Grange and Schulze 1977). ALT and DS affect the distribution of resources and conditions necessary for plant growth, such as moisture availability or temperature (Pabst and Spies 1998). There are many studies on exploring the topography-vegetation relationship (e.g., Franklin et al. 2000; Pfeffer et al. 2003; Abbate et al. 2006; Reed et al. 2009; White and Hood 2004). Topographic attributes such as ISR, ALT, S, TWI, and slope aspects are significantly correlated with vegetation changes and the individual correlations may be weak at different regions. However, these studies focus on topographic effect on vegetation type and composition, and species distribution and diversity. Deng et al. (2007) evaluated the multi-scale correlation between topographic variables and NDVI. But few studies identified which
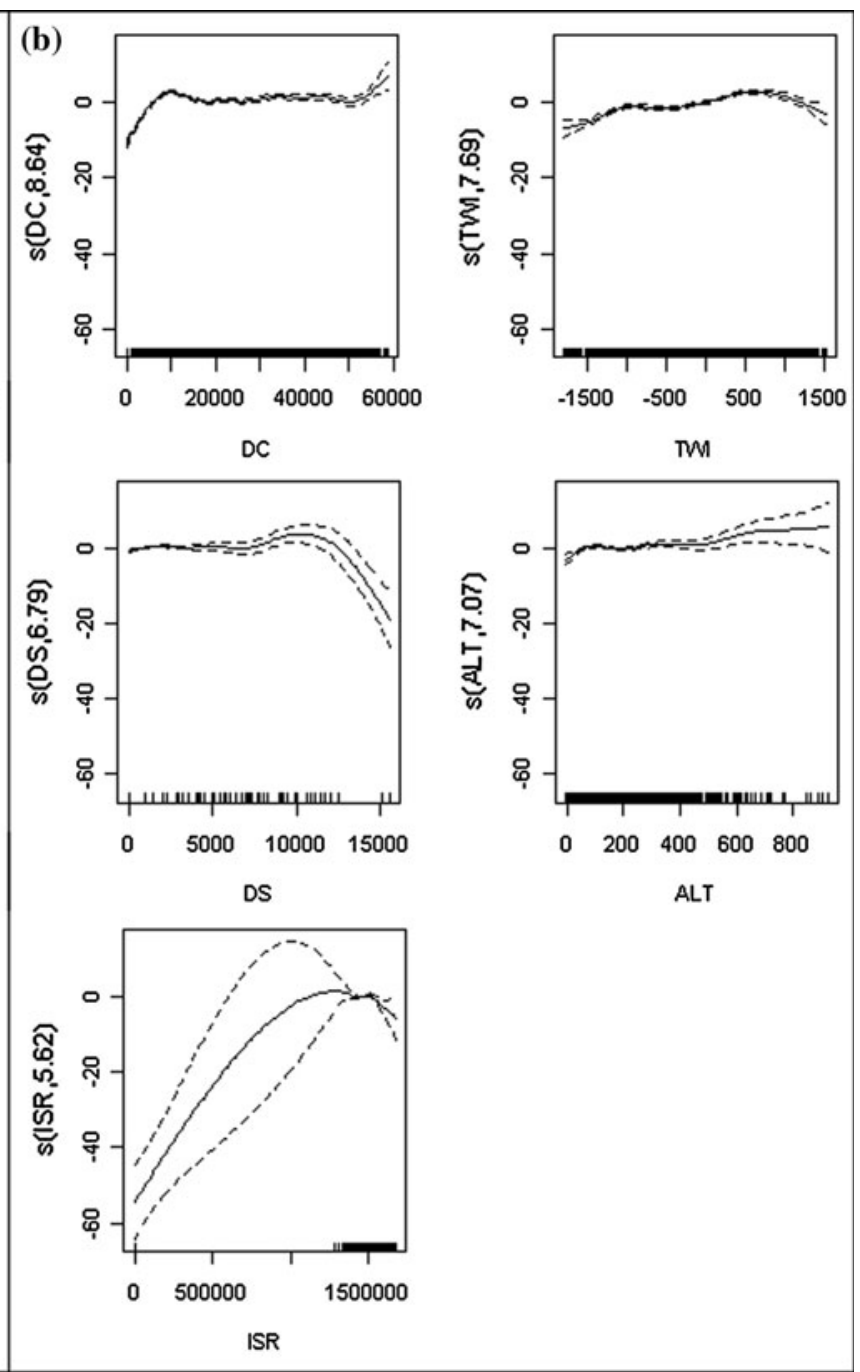

wetness index $(T W I)$, distance from the coast $(D C)$, and distance to the nearest stream $(D S)$. Dotted lines show $95 \%$ Bayesian confidence intervals

topographic environments support the highest NDVI or vegetation at landscape and regional scales. In comparison to the previous studies (Franklin et al. 2000; Pfeffer et al. 2003; Abbate et al. 2006; Reed et al. 2009; White and Hood 2004), through a data mining approach, this study explored the relative importance of topographic and topographically related variables on NDVI and identified that ALT and DS were the major influences on NDVI variation in the Jiaodong Peninsula, and TWI was the most explanatory power to the spatial variation in NDVI in woodland, cropland, and grassland landscapes.

Although topographic variables explained spatial variations in NDVI at the regional and landscape scales well, other factors can still contribute to the NDVI patterns. The relatively flat grassland and cropland landscapes may modify the influence of topography on the water conditions which are not represented by a DEM (Band et al. 1993). 

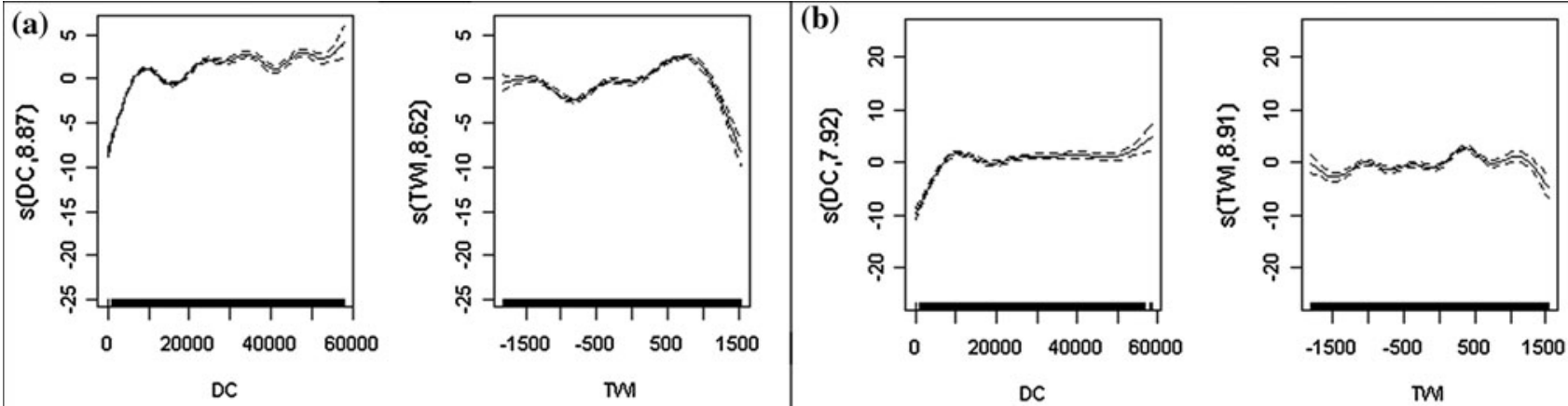

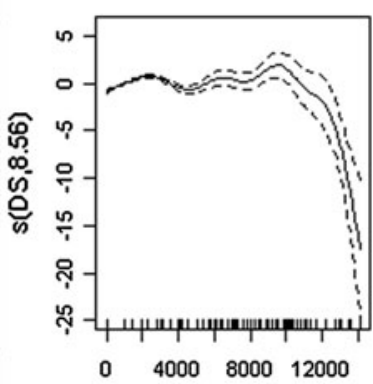

DS
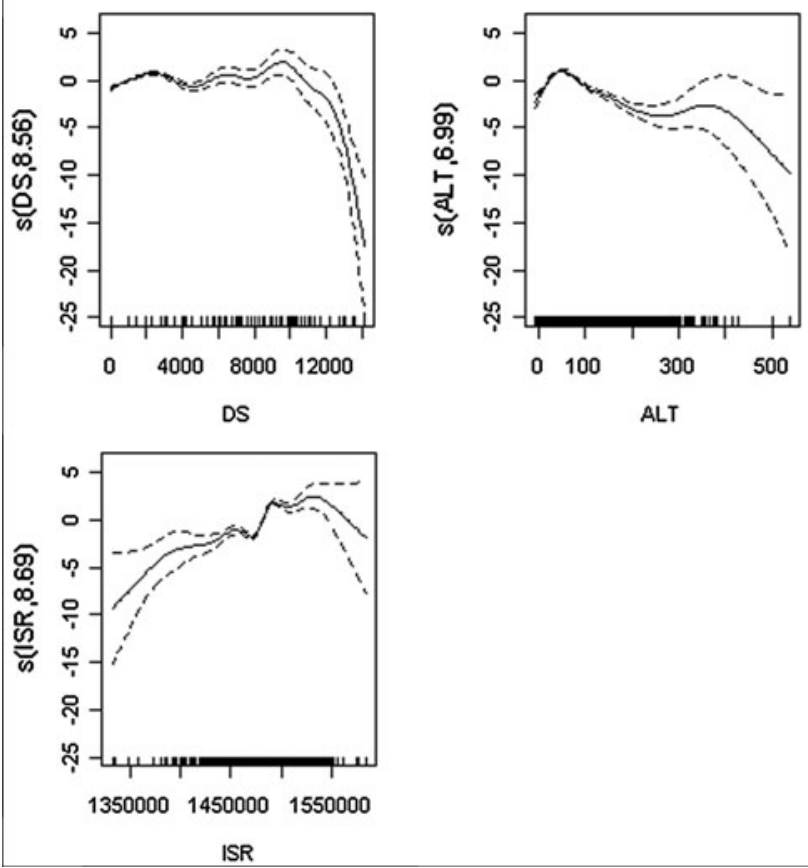

Fig. 4 Response curves of NDVI in the cropland (a) and grassland (b) to smooth contributing terms: altitude $(A L T)$, slope $(S)$, aspect $(A S)$, annual mean incident solar radiation (ISR), topographic wetness

Vegetation growth is sensitive to differences in fertility (Pugnaire and Luque 2001; Elgersma and Dhillion 2002), soil acidity (Pärtel et al. 2007), soil depth (Zelený and Chytrý 2007) and electrolytic conductivity. Additionally, the dominant vegetation type relates strongly to soil moisture retention characteristics (Jager 1982). Thus, soil attributes not accounted for in the fitted models may also have contributed to the explanation of grassland and cropland NDVI. Human activities such as urbanization, grazing and cultivation could be important contributors to the spatial variation in NDVI. It is well known that intensive agricultural managements may result in a less complex landscape structure and drastically reduce species richness in the landscape (Solstad 2006). Moreover, human population densities accounted for a significant proportion $(8.5 \%)$ of NDVI variation in the total study area, probably because species richness closely relates to human PD
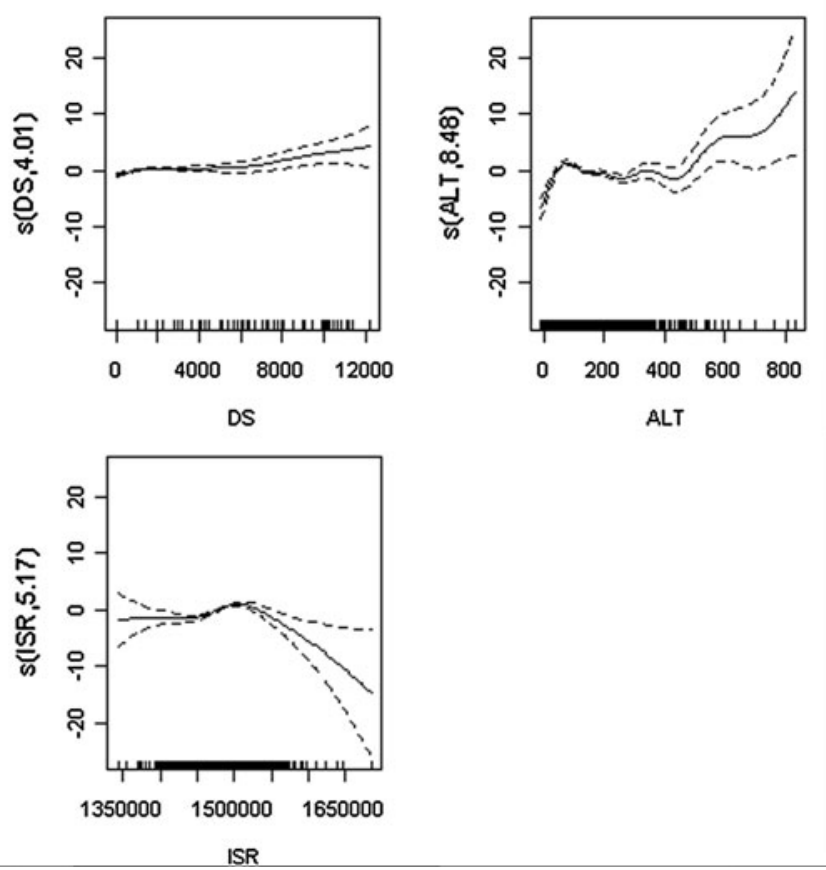

index $(T W I)$, distance from the coast $(D C)$, and distance to the nearest stream $(D S)$. Dotted lines show $95 \%$ Bayesian confidence intervals

(Duncan and Young 2000; Luck et al. 2004; Pärtel et al. 2007).

In addition, the NDVI-topography relationship may vary or be interrupted with different spatial scales, seasonal variability, selections of observed properties (Deng et al. 2007) and historic disturbance events for instance fire (Reilly et al. 2006; Kokaly et al. 2007; Fox et al. 2008). Topography often tends to play a more important role in the NDVI patterns in coarser scales (Deng et al. 2007). However, this cannot be further confirmed by this study due to the relatively low resolution of NDVI and DEM. There are different relationships and even no relationship between topography and seasonal variations in NDVI. Also, importance of topographic attributes on NDVI may change across seasons. Historic disturbance events, especially fire, can have an impact on species composition and structure (Reilly et al. 2006; Kokaly et al. 2007; Fox et al. 
2008) at micro-scales, and lead to variability in vegetation patterns at regional even global scales.

\section{Conclusions}

Spatial patterns of NDVI over the Jiaodong Peninsula and three landscapes can be well explained by topographic variables including ALT, exposure to incoming solar radiation, TWI, DS and distance from the coast. GAM is a useful tool to quantify the relationship between NDVI and topography. Based on this model, TWI was identified as the most explanatory power for spatial variation in NDVI in the woodland, cropland, and grassland landscapes. Statistical nonparametric correlation analysis shows that topography contributes to NDVI change over time and future persistence of change trends in the peninsula, cropland, grassland and woodland landscapes.

This study provides important insights into regional vegetation dynamics, and strengthens the importance of using NDVI data integrating topographic data to study vegetation heterogeneity across landscapes. However, the results can likely be further enhanced by using finer resolution spatial datasets. Furthering our understanding of direct and indirect controls such as soil attributes, climate change and human disturbance over vegetation may also improve the predictions about NDVI distribution and future variation.

Acknowledgments This work was supported by the Scientific Research Encouragement Foundation for Outstanding Young and Middle Scientist of Shandong Province (No. BS2010HZ018), Public Science and Technology Research Funds Projects of Ocean (No. 201205001), the National Natural Science Foundation of China (No. 40801016), the Knowledge Innovation Program of the Chinese Academy of Sciences (No. kzcx2-yw-224), and Taishan Scholar Position (No. TS200651036).

\section{References}

Abbate G, Cavalli RM, Pascucci S, Pignatti S, Poscolieri M (2006) Relations between morphological settings and vegetation covers in a medium relief landscape of Central Italy. Ann Geophys 49(1):153-165

Arora V (2002) Modeling vegetation as a dynamic component in soilvegetation-atmosphere transfer schemes and hydrological models. Rev Geophys 40(2):1006. doi:10.1029/2001RG000103

Band LE, Patternson P, Nemani R, Running SW (1993) Forest ecosystem processes at the watershed scale: incorporating hillslope hydrology. Agric For Meteorol 63:93-126

Berger F, Rey F (2004) Mountain protection forests against natural hazards and risks: new French developments by integrating forests in risk zoning. Nat Hazards 33:395-404

Beven KJ, Kirkby MJ (1979) A physically based, variable contributing area model of basin hydrology. Hydrol Sci Bull 24:43-69
Bio AMF, Alkemade R, Barendregt A (1998) Determining alternative models for vegetation response analysis: a nonparametric approach. J Veg Sci 9:5-16

Bledsoe BP, Shear TH (2000) Vegetation along hydrologic and edaphic gradients in a North Carolina coastal plain creek bottom and implications for restoration. Wetlands 20:126-147

Boone RB, Galvin KA, Lynn SJ (2000) Generalizing El Nino effects upon Maasai livestock using hierarchical clusters of vegetation patterns. Photogram Eng Rem Sens 66:737-744

Brang P, Schönenberger W, Ott E, Gardner RH (2001) Forests as protection from natural hazards. In: Evans $\mathrm{J}$ (ed) The forests handbook. Blackwell Science Ltd, Oxford, pp 53-81

Ceccato P, Flasse S, Tarantola S, Jacquemoud S, Gregoire JM (2001) Detecting vegetation leaf water content using reflectance in the optical domain. Remote Sens Environ 77:22-33

Cernusca A, Tappeiner U, Bahn M, Bayfield N, Chemini C, Fillat F, Graber W, Rosset M, Siegwolf R, Tenhunen J (1998) ECOMONT: an European approach for assessing ecological effects of land-use changes in mountain landscapes. In: Tappeiner U, Ruffini F, Fumai M (eds) Hydrology, water resources and ecology of mountain areas. European Academy Bozen/Bolzano, Bozen, pp 163-167

Chen D, Brutsaert W (1998) Satellite-sensed distribution and spatial patterns of vegetation parameters over a tallgrass prairie. J Atmos Sci 55(7):1225-1238

Chuvieco E, Riaño D, Aguado I, Cocero D (2002) Estimation of fuel moisture content from multitemporal analysis of landsat thematic mapper reflectance data: applications in fire danger assessment. Int J Remote Sens 23:2145-2162

Dargie TCD (1984) On the integrated interpretation of indirect site ordinations: a case study using semi-arid vegetation in southeastern Spain. Vegetation 55:37-55

Deng YX, Chen XF, Chuvieco E, Warner T, Wilson JP (2007) Multiscale linkages between topographic attributes and vegetation indices in a mountainous landscape. Remote Sens Environ 111:122-134

Douville H, Planton S, Royer JF, Stephenson DB, Tyteca S, Kergoat L, Lafont S, Betts RA (2000) Importance of vegetation feedbacks in doubled- $\mathrm{CO}_{2}$ climate experiments. J Geophys Res 105(D11): 14841-14861. doi:10.1029/1999JD901086

Duncan RP, Young JR (2000) Determinants of plant extinction and rarity 145 years after European settlement of Auckland, New Zealand. Ecology 81:3048-3061

Elgersma AM, Dhillion SS (2002) Geographical variability of relationships between forest communities and soil nutrients along a temperature-fertility gradient in Norway. Forest Eco Manag 158:155-168

Eugster W, Rouse WR, Mcfadden JP, Baldocchi DD, Stuart F, Iii C, Liston GE, Luigi Vidale P (2000) Land-atmosphere energy exchange in Arctic tundra and boreal forest: available data and feedbacks to climate. Glob Change Biol 6:84-115

Fox D, Maselli F, Carrega P (2008) Using spot images and field sampling to map burn severity and vegetation factors affecting post forest fire erosion risk. Catena 75:326-335

Franklin J (1995) Predictive vegetation mapping: geographic modeling of biospatial patterns in relation to environmental gradients. Prog Phys Geog 19:474-499

Franklin J, Woodcock CE, Warbington R (2000) Digital vegetation maps of forest lands in California: integrating satellite imagery, GIS modeling, and field data in support of resource management. Photogram Eng Rem Sens 66:1209-1217

Fu BJ, Wang YF, Lu YH, He CS, Chen LD, Song CJ (2009) The effects of land use combinations on soil erosion: a case study in the Loess Plateau of China. Prog Phys Geogr 33:793-804 
Grange JE, Schulze RE (1977) Incoming solar radiation patterns and vegetation response: examples from the Natal Drakensberg. Plant Ecol 35:47-54

Guisan A, Zimmermann NE (2000) Predictive habitat distribution models in ecology. Ecol Model 135:147-186

Guisan A, Edwards TC Jr, Hastie T (2002) Generalized linear and generalized additive models in studies of species distributions: setting the scene. Ecol Model 157:89-100

Hastie T, Tibshirani R (1987) Generalized additive model: some applications. J Am Stat Assoc 82:371-386

Hurst H (1951) Long term storage capacity of reservoirs. Trans Am Soc Civil Eng 6:770-799

Jager TJ (1982) Soils of the Serengeti woodlands, Tanzania. Agricultural University, Wageningen, pp 1-239

Keddy PA (1990) Competitive hierarchies and centrifugal organization in plant communities. In: Grace J, Tilman D (eds) Perspectives on plant competition. Academic Press, San Diego, pp 266-290

Kokaly RF, Rockwell BW, Haire SL, King TV (2007) Characterization of postfire surface cover, soils, and bum severity at the Cerro Grande Fire, New Mexico, using hyperspectral and multispectral remote sensing. Remote Sen Environ 106:305-325

Lehmann A, McOverton J, Leathwick JR (2002) GRASP: generalized regression analysis and spatial prediction. Ecol Model 157:189-207

Liu Y, Wang Q, Bi J, Zhang M, Xing Q, Shi P (2010) The analysis of NDVI trends in the coastal zone based on Mann-Kendall test: a case in the Jiaodong Peninsula. Acta Oceanologica Sinica 32:79-87 (in Chinese)

Luck GW, Ricketts TH, Daily GC, Imhoff M (2004) Alleviating spatial conflict between people and biodiversity. Proc Natl Acad Sci USA 101:182-186

Meentemeyer RK, Moody A, Franklin J (2001) Landscape-scale patterns of shrub-species abundance in California chaparral: the role of topographically mediated resource gradients. Plant Ecol 156:19-41

Morzaria-Luna H, Callaway JC, Sullivan G, Zedler JB (2004) Relationship between topographic heterogeneity and vegetation patterns in a Californian salt marsh. J Veg Sci 14:523-530

Pabst RJ, Spies TA (1998) Distribution of herbs and shrubs in relation to landform and canopy cover in riparian forests of coastal Oregon. Canadian J Bot 76:298-315

Pärtel M, Helm A, Reitalu T, Liira J, Zonbel M (2007) Grassland diversity related to the late Iron Age human population density. J Ecol 95:574-582
Peng J, Liu Z, LiuY WuJ, Han Y (2012) Trend analysis of vegetation dynamics in Qinghai-Tibet Plateau using Hurst exponent. Ecol Indic 14:28-39

Pfeffer K, Pebesma EJ, Burrough PA (2003) Mapping alpine vegetation using vegetation observations and topographic attributes. Landsc Ecol 18:759-776

Pons X (1998) Manual of Miramon. Geographic information system and remote sensing software. Centre de Recerca Ecològica I Aplicacions Forestals (CREAF), Bellaterra. Available at: http://www.creaf.uab.es/miramon

Poulos HM, Camp AE (2010) Topographic influences on vegetation mosaics and tree diversity in the Chihuahuan Desert Borderlands. Ecology 91(4):1140-1151

Pugnaire FI, Luque MT (2001) Changes in plant interactions along a gradient of environmental stress. Oikos 93:42-49

Reed BC, Brownl JF, VanderZee D, Loveland TR, Merchant JW, Ohlen DO (1994) Measuring phenological variability from satellite imagery. J Veg Sci 5:703-714

Reed DN, Anderson TM, Dempewolf J, Metzger K, Serneels S (2009) The spatial distribution of vegetation types in the Serengeti ecosystem: the influence of rainfall and topographic relief on vegetation patch characteristics. J Biogeogr 36:770-782. doi: 10.1111/j.1365-2699.2008.02017.x

Reilly MJ, Wimberly MC, Newell CL (2006) Wildfire effects on plant species richness at multiple spatial scales in forest communities of the southern Appalachians. J Veg Sci 94:118-130

Serrano L, Ustin SL, Roberts DA, Camon JA, Peñuelas J (2000) Deriving water content of chaparral vegetation from AVIRIS data. Remote Sens Environ 74:570-581

Solstad H (2006) Scale-dependent importance of environment, land use and landscape structure for species richness and composition of SE Norwegian modern agricultural landscapes. Landsc Ecol 21:969-987

Svoray T, Karnieli A (2011) Rainfall, topography and primary production relationships in a semiarid ecosystem. Ecohydrology 4:56-66

Tilman D (1982) Resource competition and community structure. Princeton University Press, Princeton

White DA, Hood CS (2004) Vegetation patterns and environmental gradients in tropical dry forests of the northern Yucatan Peninsula. J Veg Sci 15:151-160

White AB, Kumar P, Tcheng D (2005) A data mining approach for understanding topographic control on climate-induced interannual vegetation variability over the United States. Remote Sens Environ 98:1-20 